\title{
ICT based innovative solutions in building agroforestry training and learning support system
}

\author{
Miklós Herdon ${ }^{1}$, Charles Burriel ${ }^{2}$, János Tamás ${ }^{3}$, László Várallyai ${ }^{4}$, János Pancsira $^{5}$
}

\begin{tabular}{ll}
\hline I N F O & A B S T R A C T \\
Received & \\
Accepted & The aim of the AgroFE project (www.agrofe.eu) is to develop vocational training in the \\
Responsible Editor: & field of agroforestry in 6 countries: United Kingdom, Belgium, Czech Republic, \\
& Hungary, Romania and France. Several levels of training are targeted by the project, \\
levels N3-N4 relate to farmers and future farmers, levels N5 + / N6 affect (future) \\
advisors, trainers, teachers, technicians who are working in the domain. In the context of \\
Keywords: \\
e-Learning, on-line learning, \\
knowledge databank, \\
agroforestry \\
(CTC-CWS), the Knowledge Data Bank (KDB-BDC), the tools for training and a portal \\
that integrates the tools. The knowledge data bank is a component of the project training \\
system. It aims to gather and share a set of documents, resources that partners can use \\
and which will have been accessed by learners and the public users. The project focuses \\
to the newest innovative ICT solutions and trends. The knowledge data bank is to enable \\
the sharing, access and consultation in the use of certain resources for training. These \\
resources are under different forms: Mono document object (like a photo, a text, a \\
diagram) and Composite materials (for example a html web page with images, a pdf file \\
with pictures and diagrams, a video clip with images and sounds ...). The prototype of \\
the AgroFE project is based on a software, RUBEDO, developed in PHP and RUBEDO \\
is built on different components: a data base management software (DBMS-SGBD), type \\
'NoSQL', MongoDB, and the user interface uses the ElasticSearch search engine. The \\
paper describes the prototype system and the used ICT tools in the project, such as LMS \\
and the collaborative working environment.
\end{tabular}

\section{Introduction}

Depending on the countries, states or professional organizations and training actors try to reintroduce agroforestry in the course of training and qualification in initial training and adult education. Based on the results of scientific research, development structures and those of the "farmer-researchers", experimental courses were conducted in different countries, including BE, FR, in the UK on a small scale as resources, trainers and available skills are scarce. The partners have identified training needs in the short term. These needs are on the one hand operators and future operators, adults and pupils/students, teachers and counsellors, tutors. In the short term, the project will address these to public

\footnotetext{
${ }^{1}$ Miklós Herdon, professor

University of Debrecen, Debrecen, Hungary

herdon.miklos@econ.unideb.hu

${ }^{2}$ Charles Burriel, professor

AGROSUP, Dijon, France

charles.burriel@educagri.fr

3 János Tamás, professor

University of Debrecen, Debrecen, Hungary

tamas@agr.unideb.hu

${ }^{4}$ László Várallyai, associate professor

University of Debrecen, Debrecen, Hungary

varallyai.laszlo@econ.unideb.hu

${ }^{5}$ János Pancsira, software engineer

University of Debrecen, Debrecen, Hungary

pancsira.janos@econ.unideb.hu
} 
through a system established by the partners (Herdon at al. 2011) based on innovative teaching practices training, occupational situations providing access to recognized qualifications (NQF, EQF, ECVET and ECTS). Fortunately the ICT tools have been developed increasingly nowadays, so there are tools and methods for e-learning and e-collaboration (Bustos et al. 2007; Lengyel 2009; Herdon and Lengyel 2013; Herdon and Rózsa 2012). European partners from 6 countries participate in the project. One of the important parts of the project is to apply innovative solutions for building and using the web site (http://www.agrofe.eu/) and knowledge repositories for teaching and learning agroforestry.

\section{The objectives and development methods}

The main objectives are to make a synthesis of needs and expectations. The work based on the present existing training actions and to set up a common framework. Within this framework the target is to build an innovative training system (contextualized, modularized trainings, use of ICT, professionals participation), to create a technical collaborative support for the implementation of the project with communication tools (information of partners and promotion) and providing access to the resources and training services during and after the project (knowledge databank, interactive services). To achieve this objectives the following main activities have to be carried out:

- Exploitation of the tools and services.

- Building a collaborative working environment.

- Planning the architecture for development, teaching and training.

- Implementing the e-learning environment.

- Designing the multimedia tools to make the system accessible for learners, trainers.

Based on different methods we built a collaborative working environment for the project partners and players who will join to this knowledge database and information service. We used the following methods (do the following activities):

- Using the experiences from former project and practice.

- Studying new technologies and methods.

- Developing Agroforestry in agri-environment BSc course.

- Evaluating them.

- Selection.

\section{Results}

Based on our analysis related to main e-learning trends we have to state that the technology and methods are developing continuously. Of the $\$ 4.1$ trillion spent on education and training, approximately $25 \%$ is in Europe, making it the 2nd largest market to North America. In the schools market, Europe boasts $27 \%$ more teachers than the US, with 4.6 million teachers as compared to 3.6 million in the US (IBIS Capital 2013). The European e-Learning market is a highly fragmented market comprising up to 3,000 predominantly small entrepreneurial companies. The fragmentation represents in part the early stage nature of the industry and the market difference within Europe. The spent on academic education and learning outweighs the spent on corporate training by about $18 \mathrm{x}$. There is also a regional split between northern and southern Europe where for example in the Nordics workers are 4x more likely to be receiving training than in southern Europe. The perspective can be seen on the Hype Cycle (Figure 1.) 


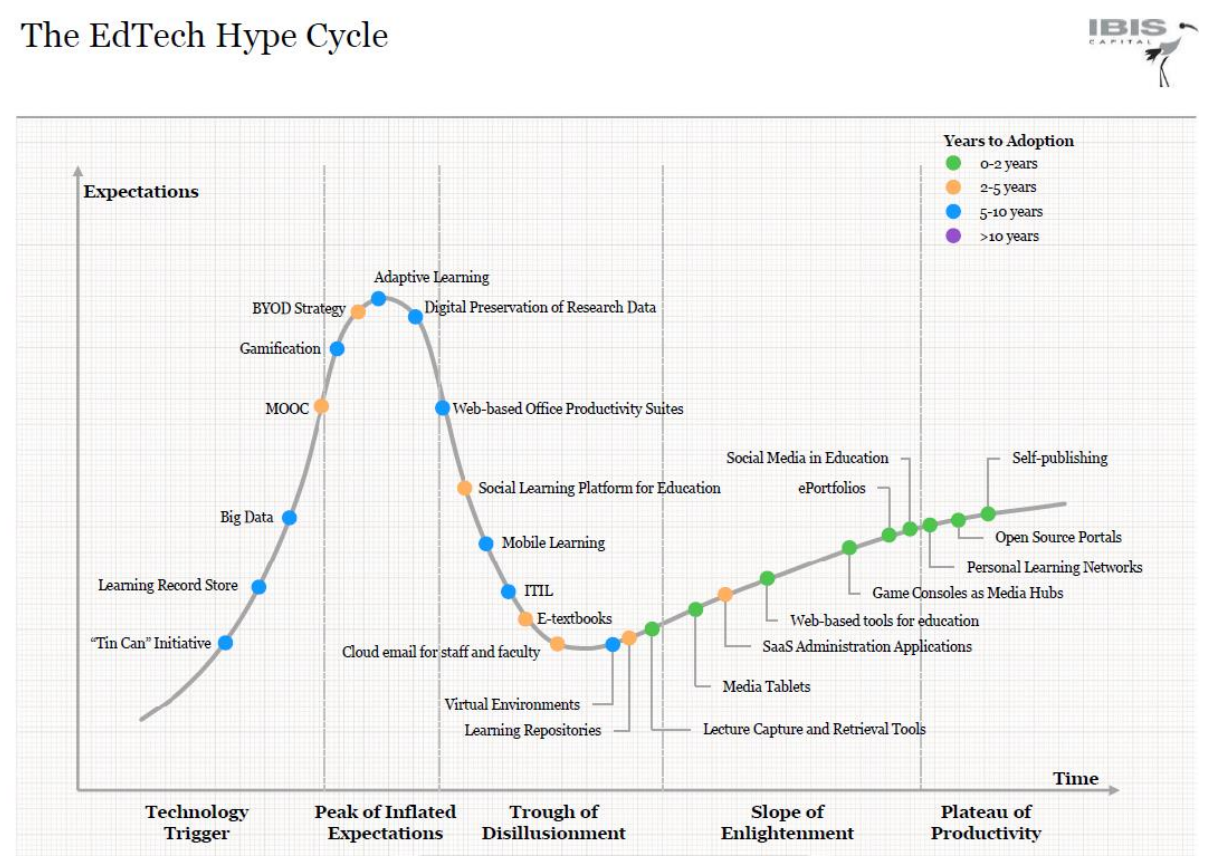

Figure 1. A European perspective on e-Learning (IBIS Capital 2013)

\subsection{Moodle Learning Management System as collaborative tools for project virtual space and e- learning}

For the collaborative working in the project we plan to use existing open source and free services. One of the essential solutions was the Moodle system which was used earlier in a similar project (Burriel 2007). One selection criterion was based on that we have more than 7 years' experience in using this popular system which can give every function that we need for collaborative working during the project. The ICT system of the project will be based on a knowledge databank service and for mobility (field) work we will use tablets with Android, IoS, Windows platforms, using the central services and apps. We just would like to highlight some new feature which will be useful in the project.

- Responsive Design, Learning on the Go.

- Power up the Cloud.

- Big Data.

- Mobile Notifications.

Moodle are continually improving their responsive themes, this will allow Moodle to be used for learning on tablets, phones and other mobile devices. The core Moodle theme is based on Bootstrap and Webanywhere recommends all users migrate to a responsive theme to allow learners to access Moodle on the go. The Moodle Bootstrap theme is now the default for any new installation of Moodle. This feature is using the logging framework, and this will allow the Moodle community to build on top of the framework to enable better reports to be gathered. The Mobile Notifications is possibly the most exciting new feature to enable 'push' learning to users on the go.

The Moodle server is used as virtual collaboration space and e-learning system. The system implemented in 2014. We created the initial structure for collaborative work and starting the e-learning courses. This time 136 users are registered (enrolled) in the system from project partners and there are 70 enrolled students in agroforestry subject at University of Debrecen.

\subsection{Vidyo, Mooc and Videotorium}

Other ICT support tools have been introduced into the project. The VidyoDesktop system extends high-quality video conferencing to different platforms of computers, allowing users on these systems to participate at their office or from home. With support encoding at resolutions up to full HD and dualscreen multipoint video, VidyoDesktop delivers a first-class conferencing experience to any workspace. 
VidyoDesktop extends high quality conferencing and collaboration to virtual desktop and thin client environments.

The benefits of the VidyoDesktop system are the following:

- Host conferences in a virtual conference room with simple click-to-connect access for both administered users and guests.

- No need for an expensive dedicated appliances.

- Multiple user-selectable layouts for active speaker, and shared content.

- In-conference public and private text chat.

- Far-end camera control of Vidyo and third-party group solutions.

Another concept in the project to use the MOOC model. A massive open online course (MOOC) is an online course aimed at unlimited participation and open access via the web. In addition to traditional course materials such as videos, readings, and problem sets, MOOCs provide interactive user forums that help build a community for students, professors, and teaching assistants. MOOCs are a recent development in distance education which began to emerge in 2012. Early MOOCs often emphasized open access features, such as connectivism and open licensing of content, structure and learning goals, to promote the reuse and remixing of resources. Some later MOOCs use closed licenses for their course materials while maintaining free access for students. On the Figure 2. can be seen the evolution of MOOC.

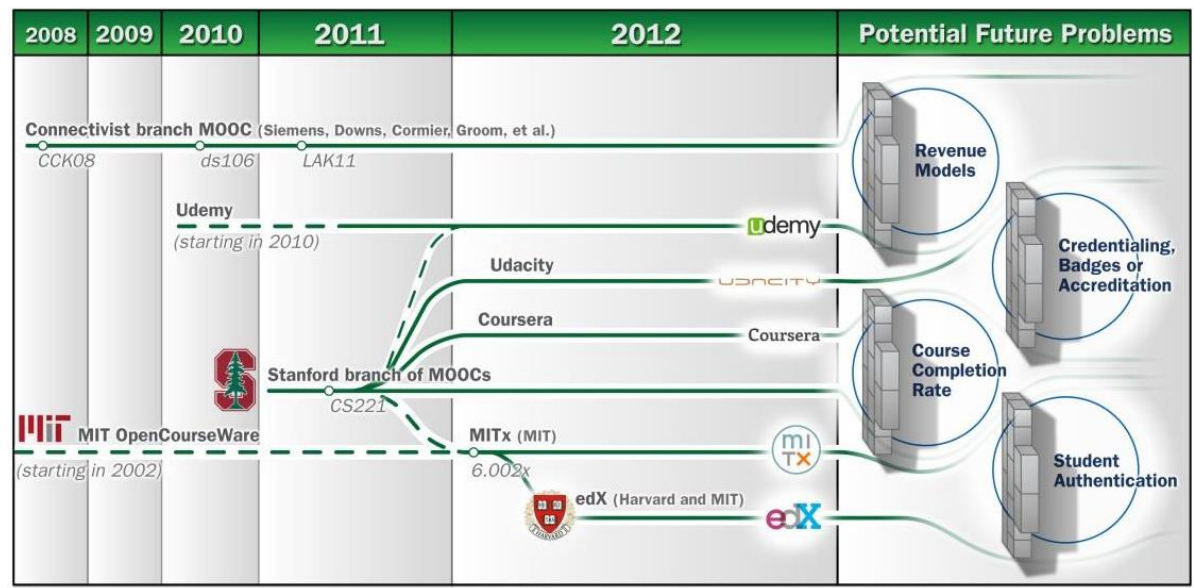

Figure 2. Evolution of MOOC (Hill 2012; Gaebel 2013)

The next tool (service) what is used in the project the Videotorium repository and service. The Videotorium would like to meet special requirements of higher-education, research and public collections community, which would be rather difficult to satisfy by a general video sharing portal. Major features briefly:

- Sharing of audio- and video recordings.

- Uploading and synchronize slides to the recording of your speech.

- Organisational micro sites: present all recordings of your institution through an own Videotorium site with individual URL, design and news.

- Flexible metadata scheme meeting requirements of scientific publication.

- Flash based playback, compatibility with all popular browsers.

- eduID federative authentication and authorization.

- Live streaming: broadcast your event live through Videotorium to deliver your event to thousands of users through our high capacity servers.

We are testing this system for storing and streaming videoconferences on-line lectures (on-line learning, Figure 3.). 


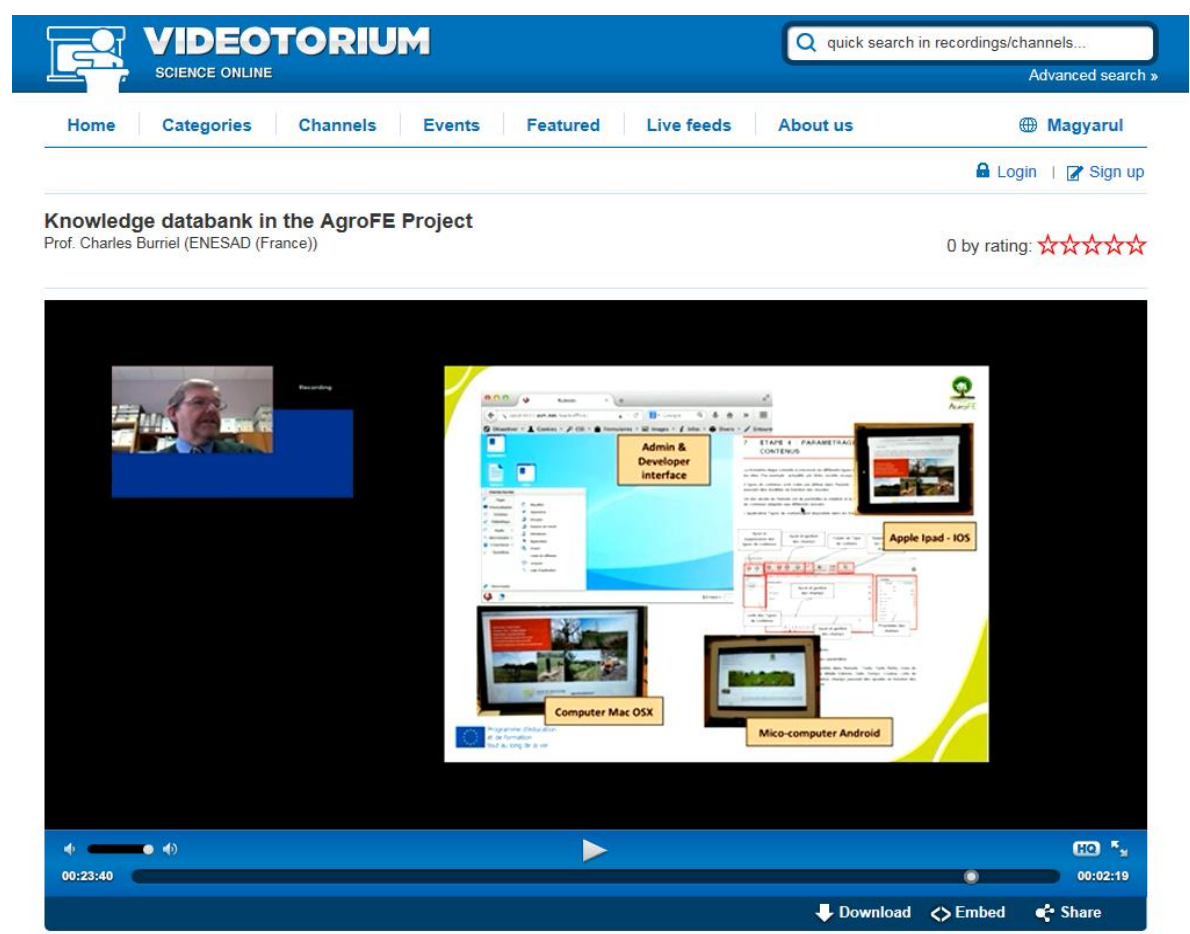

Figure 3. Playing the video from the auditorium

\subsection{Building the community on Agroforestry}

One of our task in the project are the dissemination and building a knowledge databank. We are trying to promote the project. The official project website is the following URL: http://www.agroforestry.eu. From end of the last year has been working a social network site on the Facebook (https://www.facebook.com/Agrofe) (Figure 4.).

A knowledge base or knowledge bank is a special kind of database for knowledge management. A knowledge base is an information repository that provides a means for information to be collected, organized, shared, searched and utilized. It can be either machine-readable or intended for human use. Behind a Knowledge Data Bank (KDB) there is, at least, a back-end which is a DBMS. The developed system architecture can be seen on the Figure 5.

In the context of the AgroFE project related to ICT includes four components, the collaborative tools (OTC-CWS), the Knowledge Data Bank (KDB-BDC), the tools for training (and archiving) and a portal that integrates the tools (Figure 5.).

- The KDB is to enable the sharing, access and consultation in the use of certain resources for training. These resources are under different forms:

- Mono document object, like a photo, a text, a diagram,

- Composite materials, for example a html web page with images, a "pdf" file with pictures and diagrams, a video clip, with images and sounds etc. 


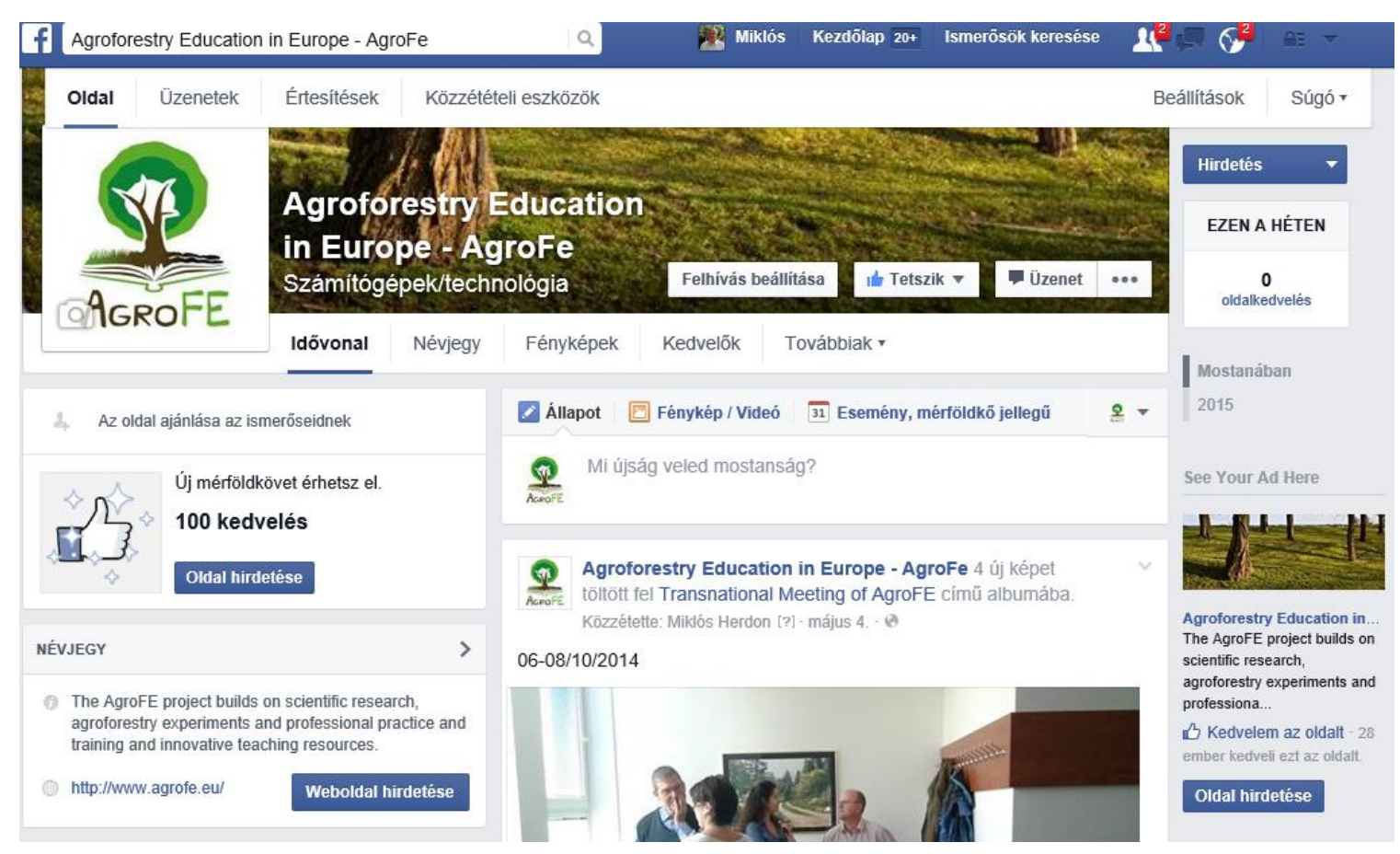

Figure 4. The Agroforestry project common network site on the Facebook

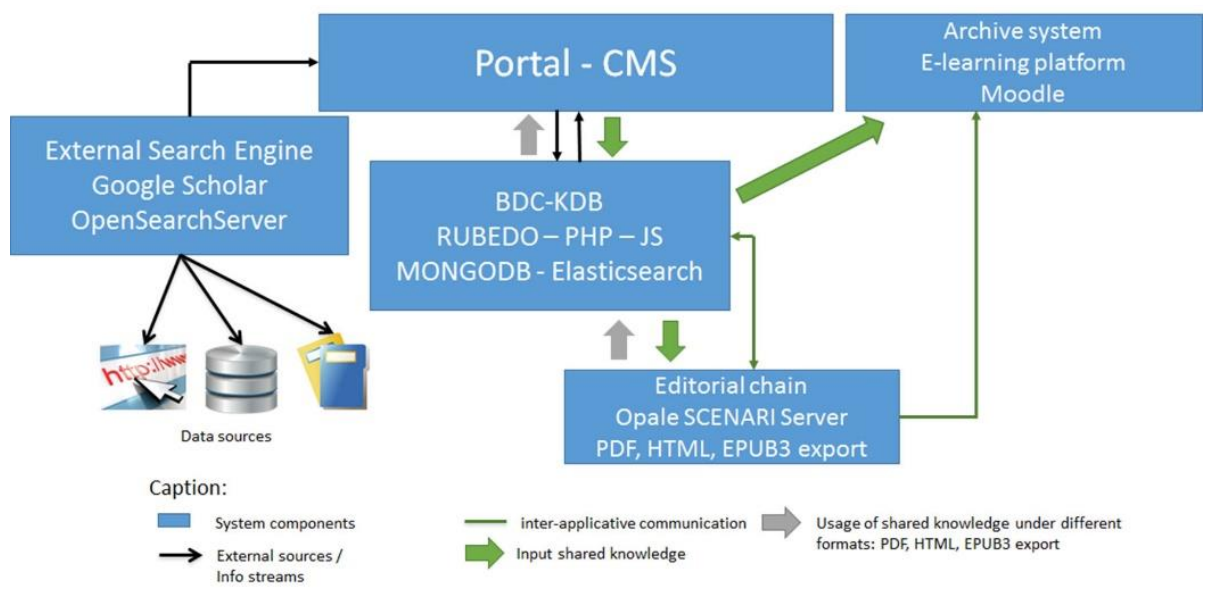

Figure 5. Knowledge Base System architecture

Under the project documents are identified, selected, proposed by partners and included into the KDB for the evaluation of their potential use in training by one or more partners. A fact sheet originally written by the proposer, the institution, who proposed it to project partners. At the end of the evaluation phase, the KDB can be extended to other contributors for other uses, such as exchange supports between different actors of Agroforestry.

In computing, a database is gathering highly structured data, a well-defined organization, based on different types of structures: relational, hierarchical. This is absolutely not the case in a databank in which we store structured tables of numbers as well as illustrated text or video or emails, external knowledge or those from the project in their various forms. But it should be noted that the knowledge data bank in the prototype of the AgroFE project is based on a software, RUBEDO developed in PHP and RUBEDO is built on different components:

- a database management software (DBMS), type 'NoSQL', MongoDB,

- the user interface uses the ElasticSearch search engine. 


\section{Conclusion}

The agroforestry will be important for rural areas and farms according to more aspects. Environmental, economic, agricultural production, rural living is very important issues. The project participants are involved in to developing curricula for more training levels. The latest version of the Moodle system has been implemented for collaborative space and we carried out more virtual meetings by the new videoconference systems, which have been tested and used more times. All the virtual meetings have been recorded in the Videotorium system. We are convinced that using the innovative technologies and solutions the system will serve and support to achieve the project goals. Analysing the open source tools we have created the architecture of the knowledge base and service system for harvesting materials, building knowledge base and information service, implement e-learning service in agroforestry. The Knowledge Data Bank and service system is developing and will be finished in this year.

\section{Acknowledgments}

This publications was supported by EU Leonardo Innovations Transfer "Agroforesterie Formation en Europe - AgroFE” Ref. Number: 2013-1-FR1-LEO05-48937 project.

\section{References}

Burriel C 2007, NODES - E-learning aspects and accessibility International. In Conference on Agricultural Economics, Rural Development and Informatics, pp. 83-91. Debrecen, Hungary.

Bustos E S, Zazueta F S, Howard H B 2007, Rapid prototyping of learning objects and their implementation using ontology editor. In Conference on Agricultural Economics, Rural Development and Informatics, pp. 59-60. Debrecen, Hungary.

Gaebel M 2013, MOOCs Massive Open Online Courses. EUA (European University Association) Occasional Papers. http://www.eua.be/Libraries/Publication/EUA_Occasional_papers_MOOCs.sflb.ashx; 2015. June.

Herdon M and Lengyel P 2013, Building and Using Knowledge Repositories for Agriculture: An Innovation Case Study. In: EFITA WCCA CIGR 2013 Conference: Sustainable Agriculture through ICT innovation, pp. 180-187. Torino, Italy.

Herdon M and Rózsa T 2012, Knowledge dissemination on innovative information technologies in agriculture. Journal of Ecoagritourism 8:(1), pp. 301-306.

Herdon M, Szilágyi R and Várallyai L 2011, ICT Tools for Implementation the European Qualification Framework in the Agricultural Sector. Journal of Agricultural Informatics 2:(1), pp. 29-40. doi: $\underline{10.17700 / j a i .2011 .2 .1 .57 ~}$

Hill P 2012, Four Barriers That MOOCs Must Overcome To Build a Sustainable Model http://mfeldstein.com/four-barriers-that-moocs-must-overcome-to-become-sustainable-model/ 2015. June.

IBIS Capital 2013, A European Perspective on e-Learning. IBIS Capital (e-Learning). http://edxusgroup.com/wp-content/uploads/2013/12/13-06-18-A-European-Perspective-on-e-Learning.pdf, 2015. June.

Lengyel P 2009, Supporting teaching and learning with e-learning tools in agriculture. JOINT International Conference: Information systems in agriculture and forestry, pp. 176-182. Prague, Czech Republic 